\title{
Coxiella Burnetii in Horses of Algeria: Seroprevalence and Associated Risk Factors
}

\author{
Samir Ansel ${ }^{1,2}$, Karima Benfodil ${ }^{3}$, Abdellah Mohamed Cherif ${ }^{4}$, Amine Abdelli $^{3}$, Rachid Kaidi ${ }^{5}$, Kamel Miroud $^{6}$, \\ and Khatima Ait-Oudhia ${ }^{1,5^{*}}$
}

${ }^{I}$ High National Veterinary School of Algiers. Laboratoire HASAQ “Hygiene Alimentaire et Systeme Assurance Qualité”, rue Issad Abbes, El Alia, Oued Smar, Algiers, Algeria.

${ }^{2}$ Djilali Bounaama University, Department of Biological science, Khemis Miliana, Algeria

${ }^{3}$ Akli Mohand Oulhadj University, Department of Agriculture Science, Bouira, Algeria

${ }^{4}$ Institute of Veterinary sciences, University of Mohamed Cherif Messadia, Souk ahras, Algeria

${ }^{5}$ University of Blida 1, Institute of Veterinary Sciences. Laboratory of Biotechnology in Animal Reproduction, Blida, Algeria

${ }^{6}$ University of El-Tarf, Institute of Veterinary Sciences. Laboratoiry « Epidémio-surveillance, santé, productions et reproduction, expérimentation et thérapie cellulaire des animaux domestiques et sauvages (ESSPRETCADS), El-Tarf, Algeria

*Corresponding author's Email: khatima.aitoudhia@gmail.com; (D) ORCiD: 0000-0002-2514-5615

\begin{abstract}
The $\mathrm{Q}$ fever is a worldwide zoonotic disease caused by Coxiella burnetii (an obligate intracellular bacterium). This pathogen affects humans, ruminants, equines, carnivores, rodents, and birds. A cross-sectional study was carried out from March 2017 to May 2018 to assess the seroprevalence and identify the risk factors of C. burnetii infection in horses (Equus Caballus) residing in three districts of Algerian, namely Tiaret, El-Bayadh, and Ghardaia. Serum samples collected from 182 horses were analyzed via enzyme-linked immunosorbent assay (ELISA). Association of seropositivity with potential risk factors related to animals (e.g., age, gender, breed, housing, and presence of ticks), breeding characteristics (e.g., geographical localization, contact with animals), and environmental characteristics (i.e., presence of water source) was analyzed by univariate and multivariate logistic regression. An overall seroprevalence of $9.9 \%$ (18/182) was obtained. The univariate analysis of risk factors for C. burnetii seroprevalence demonstrated higher seropositivity in horses that had contact with small ruminants $(\mathrm{p}=0.004)$ and dromedaries $(\mathrm{p}=0.002)$ as well as in those living near a water source $(\mathrm{p}=0.036)$ and in El-Bayadh district $(\mathrm{p}=0.005)$. The multivariate logistic regression analysis indicated that the risk of $C$. burnetii infection was significantly higher in horses that were in contact with small ruminants (RR: 15.6). Algeria is endemic for Q fever in horses and prophylactic measures must be taken to reduce /prevent its transmission to animals and humans.
\end{abstract}

Keywords: Algeria, Coxiella burnetii, ELISA, Horses, Q fever, Seroprevalence

\section{INTRODUCTION}

Coxiella burnetii is a Gram-negative obligate intracellular bacterium that causes a zoonotic disease called Q fever, which affects humans, mammalians, and non-mammalians animals. Recently, this bacterium was classified in the order Legionellales, family Coxiellaceae (Bielawska-Drózd et al., 2013). Affected animals excrete C. burnetii in their body secretions, which could directly or indirectly contaminate the environment, animals, and humans. Parturient fluids from infected animals can contaminate the environment (Tissot Dupont et al., 1992). Although one of the most important sources of this pathogen is the birth products (i.e., placenta, amniotic fluid) of infected animals, dairy products of animals (e.g., milk and cheese) have been reported to transmit C. burnetii (Maurin and Raoult, 1999). The disease is transmitted to humans and animals not only through inhalation of infected particles from goats, sheep, and cattle but also by ticks that have been strongly implicated as vectors (Duron et al., 2015). In humans, Q fever can be asymptomatic, but acute forms with pneumonia or hepatitis have been also reported (Raoult et al., 1989; Angelakis and Raoult, 2010; Eldin et al., 2017). Additionally, endocarditis, vascular, and osteoarticular infections are associated with chronic Q fever (Raoult et al., 1989; Angelakis and Raoult, 2010). Since domestic ruminants are mostly incriminated in the transmission of $C$. burnetii to humans, many epidemiological studies have been conducted throughout the world. Infected ruminants with $C$. burnetii are mainly asymptomatic and the only detectable clinical signs include abortions at the end of gestation, usually 15 days before term (Rodolakis, 2004), stillbirth, premature delivery, birth of weak offspring, agalactia, and infertility (Cetinkaya et al., 2000).

To date, the role of horses in the $\mathrm{Q}$ fever epidemiology has not been deeply investigated. In experimental conditions, horses infected with C. burnetii developed fever, depression, enteritis, and/ or bronchopneumonia (Zotov et al., 1956). Moreover, the isolation of C. burnetii from the placenta of aborted horses using molecular tests indicates a 
real involvement of the pathogen in reproductive disorders in this species (Runge et al., 2012; Roest et al., 2013). The role of horses in the transmission of $C$. burnetii to humans has been investigated. Some studies reported that people in close contact with horses, such as veterinarians and horseback riders, have more chances to be infected (Karagiannis et al., 2009; Palmela et al., 2012).

In Algeria, the zoonotic risk of $C$. burnetii has not been extensively investigated. In a study conducted by Lacheheb and Raoult (2009), the implementation of the immunofluorescence antibody test (IFAT) indicated a seroprevalence of $15.5 \%$ in humans, in Setif (northern Algeria). Recently, Ghaoui et al. (2018) identified 4 placentas affected with $C$. brunettii via IS1111 qPCR and IS30 qPCR as well as 3 seropositive individuals using IFAT out of 745 febrile spontaneous abortions in women. The findings of several studies on animals using serological tests indicated a seroprevalence range of 10-75\% in ruminants and dromedaries (Yahiaoui et al., 2013; Agag et al., 2016; Khaled et al., 2016; Benaissa et al., 2017; Djellata et al., 2019; Bellabidi et al., 2020; Menadi et al., 2020). To our knowledge, there is no report about $\mathrm{Q}$ fever infection in horses in Algeria. Therefore, the present study aimed to assess the seroprevalence of C. burnetii in horses in three Algerian districts (i.e., Tiaret, El-Bayadh, and Ghardaia) and to identify the potential risk factors associated with $C$. burnetii infection in horses.

\section{MATERIALS AND METHODS}

\section{Ethical approval}

Risk assessment was submitted to and approved by the ethics committee of the Algerian Ministry of the Interior, the Local Government and the Algerian Ministry of Agriculture and Rural Development. Blood sampling was performed by a qualified veterinarian according to the guidelines for the care and use of the animal.

\section{Study area and sample collection}

The study was carried out in the three following Algerian districts (called Wilayas), namely Tiaret (North West), El-Bayadh (Southwest), and Ghardaïa (South) as indicated in Figure 1. The study covers an area of $185648 \mathrm{~km}^{2}$

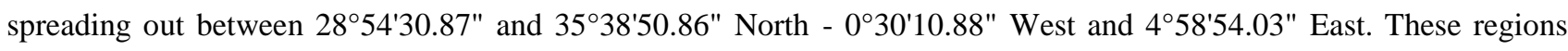
were chosen for their high concentration in horse breeding used for traditional events and production. The samples in the current study consisted of 182 horses randomly chosen from March 2017 to May 2018. The blood samples (approximately $5 \mathrm{ml}$ ) were taken through the jugular vein using vacutainer tubes. Sera were obtained by centrifugation at $3000 \mathrm{rpm}$ for $10 \mathrm{~min}$ and stored at $-20^{\circ} \mathrm{C}$ until serological analysis. 


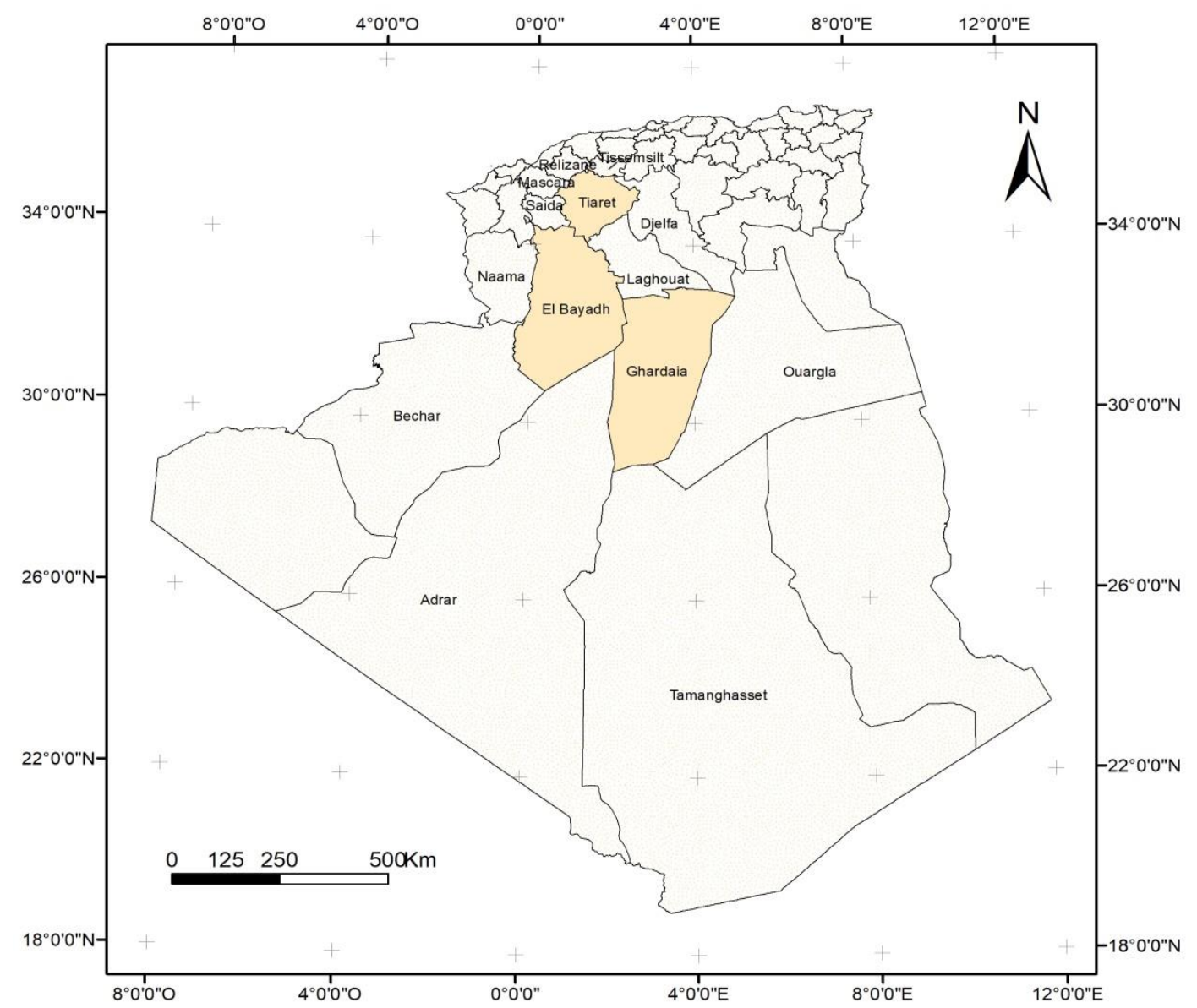

Figure 1. Location of Algerian districts for sample collection

\section{Serologic test}

The collected serum samples were tested for the presence of anti-C. burnetii antibodies via enzyme-linked immunosorbent assays (ELISA) using a commercial kit (ELISA-ID Screen ${ }^{\circledR} Q$ Fever Indirect Multi-species, IDVet, Montpellier, France) according to the manufacturer's instructions. The reaction was quantified by a spectrophotometer reading at $450 \mathrm{~nm}$ (Biotek Instruments Inc., USA). The results were reported in the optical density (OD) value. The interpretation of the results provided by the supplier (IDVet) is based on the value index. Samples were considered negative in case the OD was lesser than 40\%, questionable when OD was between $40 \%$ and $50 \%$, positive in case OD was higher than 50\%. Two control serums (positive and negative) delivered by the manufacturer were used to validate the test.

\section{Questionnaire}

The recorded data was collected directly from the owners of the horses through questionnaire and included the demographic information of animals (age, gender, breed, housing, and presence of ticks), their breeding characteristics (geographical localization, contact with small ruminants and dromedaries), and environmental characteristics (presence of water source up to $1 \mathrm{~km}$ away).

\section{Statistical analysis}

The data were analyzed using R Studio (version 1.1.383, R Studio Inc., Boston, MA, USA). Seroprevalence was calculated by dividing the number of animals possessing anti-C. burnetii antibodies by the total number of the investigated animals. The explanatory variables were categorized as age $(<5,5-10,>10$ years), gender (male, female), breed (Arabian, barb, Arab/barb, thoroughbred English), housing (box, stable), presence of ticks on animal body (yes, no), contact with ruminants (yes, no), contact with dromedaries (yes, no), presence of water source (yes, no), geographic location (Tiaret, El-Bayadh, Ghardaïa). Univariate analysis was used to analyze risk factors associated with seroprevalence. Multivariate logistic regression analysis was used to test the strength of association between the risk factors and $C$. burnetii infection using the generalized linear models (GLM). The best-fitting model to the dataset was constructed with a backward stepwise approach. The Akaike information criterion (AIC) was recruited to assess the multivariate model and the lowest AIC was used to select the best model. $P$-value less than 0.05 was considered statistically significant. 


\section{RESULTS}

\section{Seroprevalence}

Out of 182 horses' sera examined, 18 (9.9\%) samples were seropositive for C. burneti antibodies.

\section{Risk factors}

Results of the univariate analysis of risk factors for $C$. burnetii seroprevalence in horses in the study area are summarized in Table 1. Proximity of horses with dromedaries and small ruminants was significantly associated with seropositivity $(\mathrm{p}<0.05)$. Horses in contact with small ruminants and dromedaries had a higher risk of $C$. burnetii infection (15.4\% and $17 \%$, respectively), compared to those that had no contact with these two species. A higher risk of C. burnetii infection $(14.1 \%$ ) occurred in horses raised near watering points, compared to those that were farther. The close contact between watering points and horses significantly increased the seropositivity $(\mathrm{p}=0.036)$. Seroprevalence was significantly different from one Wilaya to another $(\mathrm{p}=0.005)$. This value was the highest in El-Bayadh (18.6\%), followed by Ghardaïa (10.5\%) and Tiaret (3.2\%). Table 2 tabulates the obtained results of the logistic regression analysis. The potential risk factor related to the proximity with small ruminants indicated that $C$. burnetii infection was higher in horses that were in contact with small ruminants with a relative risk of $15.6 \%(95 \% \mathrm{CI}=1.87-130.02)$.

Table 2. The factors influencing the risk of Coxiella burnetii seropositivity in horses.

\begin{tabular}{lcccc} 
Risk factors & Category & RR & $\mathbf{9 5 \%}$ confidence interval & p-value \\
\hline Contact with small ruminants & Yes & $\begin{array}{l}15.6 \\
\text { Ref }\end{array}$ & $\begin{array}{c}1.87-130.02 \\
\text { Ref }\end{array}$ & 0.006 \\
\hline Watering points & Yes & $\begin{array}{l}0.35 \\
\text { Ref }\end{array}$ & $\begin{array}{c}0.1-2.25 \\
\text { Ref }\end{array}$ & 0.17 \\
\hline
\end{tabular}

RR: Risk ratio 
Table 1. Univariable analysis of risk factors of Coxiella burnetii seropositivity in horses.

\begin{tabular}{|c|c|c|c|c|c|}
\hline Risk factors & Category & Total No. & Seropositive No. & $\begin{array}{c}\text { Seroprevalence \% }(95 \% \\
\text { confidence interval) }\end{array}$ & p-value \\
\hline \multirow{3}{*}{ Age } & $<5$ & 59 & 7 & $11.9(3.6-20.1)$ & \multirow{3}{*}{0.660} \\
\hline & {$[5-10]$} & 79 & 6 & $7.6(1.8-13.4)$ & \\
\hline & $>10$ & 44 & 5 & $11.4(2-20.7)$ & \\
\hline \multirow{2}{*}{ Gender } & Female & 173 & 18 & $10.4(5.8-14.9)$ & \multirow{2}{*}{0.308} \\
\hline & Male & 9 & 0 & 0 & \\
\hline \multirow{3}{*}{ Breed } & Arab & 56 & 2 & $3.6(0-8.4)$ & \multirow{3}{*}{0.129} \\
\hline & Barb & 72 & 8 & $11.1(3.9-18.4)$ & \\
\hline & Arabe-Barbe & 54 & 8 & $14.8(5.3-24.3)$ & \\
\hline \multirow[b]{2}{*}{ Housing } & Box & 76 & 5 & $6.6(1-12.2)$ & \multirow[b]{2}{*}{0.205} \\
\hline & Stable & 106 & 13 & $12.3(6-18.5)$ & \\
\hline \multirow[b]{2}{*}{ Contact with dromedaries } & Yes & 88 & 15 & $17(9.2-24.9)$ & \multirow[b]{2}{*}{0.002} \\
\hline & No & 94 & 3 & $3.2(0-6.7)$ & \\
\hline \multirow{2}{*}{ Contact with small ruminants } & Yes & 104 & 16 & $15.4(8.5-22.3)$ & \multirow{2}{*}{0.004} \\
\hline & No & 78 & 2 & $2.6(0-6.1)$ & \\
\hline \multirow{2}{*}{ Presence of watering points } & Yes & 99 & 14 & $14.1(7.3-21)$ & \multirow{2}{*}{0.036} \\
\hline & No & 83 & 4 & $4.8(2-9.4)$ & \\
\hline \multirow{2}{*}{ Presence of ticks } & Yes & 106 & 13 & $12.3(6-18.5)$ & \multirow{2}{*}{0.205} \\
\hline & No & 76 & 5 & $6.6(1-12.2)$ & \\
\hline \multirow{3}{*}{ Geographic localization (Algeria district) } & Tiaret & 93 & 3 & $3.2(0-6.8)$ & \multirow{3}{*}{0.005} \\
\hline & El-Bayadh & 70 & 13 & $18.6(9.5-27.7)$ & \\
\hline & Ghardaïa & 19 & 2 & $10.5(0-24.3)$ & \\
\hline
\end{tabular}

No: Number 


\section{DISCUSSION}

The $C$. burnetii has been reported in domestic animals, including sheep, goats, bovines, and dromedaries, (Dechicha et al., 2010; Yahiaoui et al., 2013; Agag et al., 2016; Khaled et al., 2016; Benaissa et al., 2017; Bellabidi et al., 2020; Menadi et al., 2020) as well as humans (Benslimani et al., 2005; Ghaoui et al., 2018) residing in Algeria. However, the present study was the first report of $C$. burnetii in horses and risk factors associated with $C$. burnetii infection in horses. Among 182 tested horses, a seroprevalence of $9.9 \%$ was obtained. This value is comparable to the pooled seroprevalence of $16 \%$ estimated throughout different areas of the word (Marenzoni et al., 2013). Higher rates of C. burnetii infection in horses were reported using molecular tests in different countries. Using PCR, a $42.2 \%$ rate of prevalence following abortions in horses was recorded in Croatia (Račić et al., 2014) and 7.7\% was recorded in the aborted or non-aborted placenta in the Netherlands (Roest et al., 2013). Using loop-mediated isothermal amplification, a prevalence of $22.2 \%$ was observed in horse blood samples in China (Pan et al., 2013). Lower rates were observed via the use of complement fixation test in the horses' sera (0\%) in Denmark (Agerholm et al., 2015) and by real-time PCR in aborted fetuses in France (1.5\%) (Leon et al., 2012).

In Algeria, the observed seroprevalence in horses was lower, compared to the reported values in Cattle (10-29\%, Dechicha et al., 2010; Agag et al., 2016; Khaled et al., 2016; Menadi et al., 2020), in dromedaries 71-75\%, (Benaissa et al., 2017; Bellabidi et al., 2020), and in small ruminants 14-23\%, (Yahiaoui et al., 2013; Khaled et al., 2016). The present study indicated that horses from El-Bayadh had a significantly higher risk of being infected (18.6\%), compared to those of Ghardaïa (10.5\%), and Tiaret $(3.2 \%)$. This discrepancy in the obtained results of various studies on the prevalence of $C$. burnetii can be due to many risk factors, such as the presence of tick vectors, climatic conditions, management practices, control measures, presence of infected animals in the horses' vicinity, and size of samples across different study areas. The prevalence differences were observed in small ruminants residing in different regions of other countries (Ullah et al., 2019; Aljafar et al., 2020).

Horses living near watering points were among the ones with the highest rate of infection. As reported, water proximity in Algeria allowed the proliferation of vectors, such as ticks, to transmit C. burnetii (Bessas et al., 2016; Leulmi et al., 2016; Aouadi et al., 2017). The contact of horses with small ruminants was a real risk factor for being seropositive to C. burnetii. The obtained result of the current study was indicative of the relative risk of $15.6 \%$ (95\% CI $=1.87-130.02$ ) for contracting the disease when horses were in contact with small ruminants. Small ruminants were considered as a reservoir and shedders of $C$. burnetii (Mertens et al., 2017). Since C. burnetii is resistant in the environment (Marrie and Raoult, 1997; Tissot Dupont et al., 1999), common spaces to horses and small ruminants become an important source of contamination. Our findings were in agreement with those of Menadi et al. (2020) and Keshavamurthy et al. (2020) investigating cattle, Maurin and Raoult (1999) and Rizzo et al. (2016) examining small ruminants. However, Benaissa et al. (2017) and Selim and Ali (2020) reported no significant relationship between Q fever infection in dromedaries and contact with small ruminants. In the current study, the contact of horses with dromedaries was identified as a risk factor for $C$. burnetii infection. Previous studies reported that dromedaries were important reservoirs of $C$. burnetii infection in the investigated areas (Benaissa et al., 2017; Bellabidi et al., 2020), and therefore, their proximity with horses increased the risk of contamination.

The findings of the current study indicated no significant association between the presence of ticks and Q fever infection which was supported by other researchers (Menadi et al., 2020; Selim and Ali, 2020). Previous studies, however, indicated that the presence of ticks increased the risk of infection by C. burnetii (Toledo et al., 2008; Benaissa et al., 2017). The role of ticks in the epidemiology of $\mathrm{Q}$ fever has been well documented, C. burnetii DNA was identified in about 40 species of ticks (Porter et al., 2011). It is well established that ticks play an important role in the sylvatic cycle of $C$. burnetii and in the contamination of humans and animals (Maurin and Raoult, 1999).

Age and gender in the current study were other insignificant risk factors, which were also reported in an earlier study on horses in South Korea (Seo et al., 2016). In ruminants, females were shown to be more infected with C. burnetii than males due to hormonal differences (Cetinkaya et al., 2000; Mazeri et al., 2013; Aljafar et al., 2020). Considering ruminants and dromedaries, aged animals are the most infected (McCaughey et al., 2010; Muskens et al., 2011), which could be due to the long duration of exposure to the pathogen. Also, there was no significant relationship between horse breed and Q fever infection. Although no exact explanation can be given, genetic predisposition is postulated as a reason. The type of horse sheltering was not associated with the infection of horses although keeping them in individual boxes could decrease the risk of tick-borne infections.

In this study, ELISA detected only IgG, thus it is difficult to differentiate between current and old infections, the use of more adequate tests in horses as molecular tests is highly recommended.

\section{CONCLUSION}


The obtained results of the current study indicated that $C$. burnetii was endemic in horses in the study areas. El-Bayadh with a seroprevalence of $18.6 \%$ was the most infected area. The contact with small ruminants and dromedaries, living near water sources, and geographical location were identified as risk factors for C. burnetii seropositivity in horses. It is supported that horses can play an important role in the transmission of the pathogen to other animals and humans. Therefore, molecular characterization of $C$. burnetii strains is recommended to compare strains isolated from horses with those from humans.

\section{DECLARATIONS}

\section{Author's contributions}

Ansel Samir conceived the study design, carried out laboratory work, participated in data analysis and interpretation, drafted the manuscript. Benfodil Karima conceived the study design, participated in data analysis and interpretation, revised the manuscript. Miroud Kamel revised the manuscript. Mohamed-Cherif Abdellah carried out laboratory work, participated in data analysis and interpretation. Abdelli Amine participated in statistical analysis and interpretation and revised the manuscript. Kaidi Rachid carried out laboratory work and revised the manuscript. AitOudhia Khatima conceived the study design, took part in the coordination and management as well as field studies, participated in data analysis and interpretation, and revised the manuscript.

\section{Competing interests}

The authors declare that they have no conflict of interest.

\section{Acknowledgments}

The authors wish to thank the Algerian Ministry of Higher Education and Scientific Research for their contribution to my Ph.D. training and Dr. Benbouras Mohamed Amin of the high national polytechnic School of Algiers for making up the geographical maps.

\section{REFERENCES}

Agag S, Kaidi R, and Khelef D (2016). Séroprévalence de la fièvre Q chez les bovins de la région de Bejaïa (Algérie). Revue d'élevage et de médecine vétérinaire des pays tropicaux, 69: 155-159. DOI: https://doi.org/10.1007/s11250-020-02295-6

Agerholm JS, Svejstrup CA, Christoffersen A-B, and Agger JFG (2015). Apparent seroprevalence for Coxiella burnetii in the Danish horse population. Dansk Veterinaertidsskrift, 98:26-29. Available at: https://www.forskningsdatabasen.dk/en/catalog/2468265634

Aljafar A, Salem M, Housawi F, Zaghawa A, and Hegazy Y (2020). Seroprevalence and risk factors of Q-fever (C. burnetii infection) among ruminants reared in the eastern region of the Kingdom of Saudi Arabia. Tropical Animal Health Production, 52: 2631-2638. DOI: https://doi.org/10.1007/s11250-020-02295-6.

Angelakis E, and Raoult D (2010). Q fever. Veterinary Microbiology, 140:297-309. DOI: https://doi.org/10.1016/j.vetmic.2009.07.016

Aouadi A, Leulmi H, Boucheikhchoukh M, Benakhla A, Raoult D, and Parola P (2017). Molecular evidence of tick-borne hemoprotozoan-parasites (Theileria ovis and Babesia ovis) and bacteria in ticks and blood from small ruminants in Northern Algeria. Comparative Immunology, Microbiology and Infectious Diseases, 50: 34-39. DOI: https://doi.org/10.1016/j.cimid.2016.11.008

Bellabidi M, Benaissa MH, Bissati-Bouafia S, Harrat Z, Brahmi K, and Kernif T (2020). Coxiella burnetii in camels (Camelus dromedarius) from Algeria: Seroprevalence, molecular characterization, and ticks (Acari: Ixodidae) vectors. Acta Tropica, 206:105443. DOI: https://doi.org/10.1016/j.actatropica.2020.105443

Benaissa MH, Ansel S, Mohamed-Cherif A, Benfodil K, Khelef D, Youngs, CR, Kaidi R, and Ait-Oudhia K (2017). Seroprevalence and risk factors for Coxiella burnetii, the causative agent of Q fever in the dromedary camel (Camelus dromedarius) population in Algeria. Onderstepoort Journal of Veterinary Research, 84:1-7. DOI: https://doi.org/10.4102/ojvr.v84i1.1461

Benslimani A, Fenollar F, Lepidi H, and Raoult D (2005). Bacterial Zoonoses and Infective Endocarditis, Algeria. Volume 11, Number 2 February, Emerging Infectious Diseases journal, CDC. DOI: https://doi.org/10.3201/eid1102.040668

Bessas A, Leulmi H, Bitam I, Zaidi S, Ait-Oudhia K, Raoult D, and Parola P (2016). Molecular evidence of vector-borne pathogens in dogs and cats and their ectoparasites in Algiers, Algeria. Comparative Immunology, Microbiology and Infectious Diseases, 45:23-28. DOI: https://doi.org/10.1016/j.cimid.2016.01.002

Bielawska-Drózd A, Cieślik P, Mirski T, Bartoszcze M, Knap JP, Gaweł J, and Żakowska D (2013). Q fever--selected issues. Annuals of Agricultural and Environmental Medicine, 20: 222-232. Available at:http://yadda.icm.edu.p1/yadda/element/bwmeta1.element.agro-eac740fc-d15e-439d8343-6bb91e70d111

Cetinkaya B, Kalender H, Ertas HB, Muz A, Arslan N, Ongor H, and Gurcay M (2000). Seroprevalence of coxiellosis in cattle, sheep and people in the east of Turkey. Veterinary Record, 146: 131-136. DOI: https://doi.org/10.1136/vr.146.5.131

Dechicha A, Gharbi S, Kebbal S, Chatagnon G, Tainturier D, Ouzrout R, and Guetarni D (2010). Serological survey of etiological agents associated with abortion in two Algerian dairy cattle breeding farms. Journal of Veterinary Medicine and Animal Health, 2: 1-5. DOI: https://doi.org/10.5897/JVMAH.9000024

Djellata N, Yahimi A, Hanzen C, Saegerman C, and Kaidi R (2019). Prevalence and factors associated with a higher or lower risk of exposure to Coxiella burnetii, Chlamydia abortus and Toxoplasma gondii in dairy cows that have aborted in Algeria. Revue Scientifique Et Technique (International Office of Epizootics), 38: 761-786. DOI: https://doi.org/10.20506/rst.38.3.3025

Duron O, Noël V, McCoy KD, Bonazzi M, Sidi-Boumedine K, Morel O, Vavre F, Zenner L, Jourdain E, Durand P et al. (2015). The recent evolution of a maternally-inherited endosymbiont of ticks led to the emergence of the Q Fever pathogen, Coxiella burnetii. PLOS Pathogens, 11:e1004892. DOI: https://doi.org/10.1371/journal.ppat.1004892

Eldin C, Mélenotte C, Mediannikov O, Ghigo E, Million M, Edouard S, Mege J-L, Maurin M, and Raoult D (2017). From Q fever to Coxiella burnetii infection: a Paradigm change. Clinical Microbiology Reviews, 30:115-190. DOI: https://doi.org/10.1128/CMR.00045-16 
Ghaoui H, Bitam I, Ait-Oudhia K, Achour N, Saad-Djaballah A, Saadnia FZ, Kedjour S, and Fournier P-E (2018). Coxiella burnetii infection with women's febrile spontaneous abortion reported in Algiers. New Microbes and New Infections, 26: 8-14. DOI: https://doi.org/10.1016/j.nmni.2018.08.003

Karagiannis I, Schimmer B, Van Lier A, Timen A, Schneeberger P, Van Rotterdam B, De Bruin A, Wijkmans C, Rietveld A, and Van Duynhoven Y (2009). Investigation of a Q fever outbreak in a rural area of The Netherlands. Epidemiology \& Infection, 137: 1283-1294. DOI: https://doi.org/10.1017/S0950268808001908

Keshavamurthy R, Singh BB, Kalambhe DG, Aulakh RS, and Dhand NK (2020). Identification of risk factors associated with Coxiella burnetii infection in cattle and buffaloes in India. Preventive Veterinary Medicine, 181:105081. DOI: https://doi.org/10.1016/j.prevetmed.2020.105081

Khaled H, Sidi-Boumedine K, Merdja S, Dufour P, Dahmani A, Thiéry R, Rousset E, and Bouyoucef A (2016). Serological and molecular evidence of Q fever among small ruminant flocks in Algeria. Comparative Immunology, Microbiology and Infectious Diseases, 47:19-25. DOI: https://doi.org/10.1016/j.cimid.2016.05.002

Lacheheb A, and Raoult D (2009). Seroprevalence of Q-fever in Algeria. Clinical Microbiology and Infection, 15:167-168. DOI: https://doi.org/10.1111/j.1469-0691.2008.02211.x

Leon A, Richard E, Fortier C, Laugier C, Fortier G, and Pronost S (2012). Molecular detection of Coxiella burnetii and Neospora caninum in equine aborted foetuses and neonates. Preventive Veterinary Medicine, 104:179-183. DOI: https://doi.org/10.1016/j.prevetmed.2011.11.001

Leulmi H, Aouadi A, Bitam I, Bessas A, Benakhla A, Raoult D, and Parola P (2016). Detection of Bartonella tamiae, Coxiella burnetii and rickettsiae in arthropods and tissues from wild and domestic animals in northeastern Algeria. Parasites \& Vectors, 9:27. DOI: https://doi.org/10.1186/s13071-016-1316-9

Marenzoni ML, Stefanetti V, Papa P, Casagrande Proietti P, Bietta A, Coletti M, Passamonti F, and Henning K (2013). Is the horse a reservoir or an indicator of Coxiella burnetii infection? Systematic review and biomolecular investigation. Veterinary Microbiology, 167: 662-669. DOI: https://doi.org/10.1016/j.vetmic.2013.09.027

Marrie TJ, and Raoult D (1997). Q fever--a review and issues for the next century. International Journal of Antimicrobial Agents, 8:145-161. DOI: https://doi.org/10.1016/s0924-8579(96)00369-x

Maurin M and Raoult D (1999). Q fever. Clinical Microbiology Reviews, 12:518-553. DOI: https://doi.org/10.1128/CMR.12.4.518

Mazeri S, Scolamacchia F, Handel IG, Morgan KL, Tanya VN, and Bronsvoort BM dec (2013). Risk factor analysis for antibodies to Brucella, Leptospira and C. burnetii among cattle in the Adamawa Region of Cameroon: a cross-sectional study. Tropical Animal Health and Production, 45: 617-623. DOI: https://doi.org/10.1007/s11250-012-0268-0

McCaughey C, Murray LJ, McKenna JP, Menzies FD, McCullough SJ, O’Neill HJ, Wyatt DE, Cardwell CR, and Coyle PV (2010). Coxiella burnetii (Q fever) seroprevalence in cattle. Epidemiology and Infection, 138: 21-27. DOI: https://doi.org/10.1017/S0950268809002854

Menadi SE, Mura A, Santucciu C, Ghalmi F, Hafsi F and Masala G (2020). Seroprevalence and risk factors of Coxiella burnetii infection in cattle in northeast Algeria. Tropical Animal Health and Production, 52: 935-942. DOI: https://doi.org/10.1007/s11250-019-02083-x

Mertens K, Gerlach C, Neubauer H, and Henning K (2017). Q fever - An update. Current Clinical Microbiology Reports, 4:61-70. DOI: https://doi.org/10.1007/s40588-017-0059-5

Muskens J, Engelen E van, Maanen C van, Bartels C, and Lam TJGM (2011). Prevalence of Coxiella burnetii infection in Dutch dairy herds based on testing bulk tank milk and individual samples by PCR and ELISA. Veterinary Record, 168:79. DOI: https://doi.org/10.1136/vr.c6106

Palmela C, Badura R, and Valadas E (2012). Acute Q fever in Portugal. Epidemiological and clinical features of 32 hospitalized patients. Germs, 2: 43 59. DOI: https://doi.org/10.11599/germs.2012.1013

Pan L, Zhang L, Fan D, Zhang X, Liu H, Lu Q, and Xu Q (2013). Rapid, simple and sensitive detection of Q fever by loop-mediated isothermal amplification of the htpAB gene. PLoS neglected Tropical Diseases, 7: e2231. DOI: https://doi.org/10.1371/journal.pntd.0002231

Porter SR, Czaplicki G, Mainil J, Guattéo R, and Saegerman C (2011). Q fever: current state of knowledge and perspectives of research of a neglected zoonosis. International Journal of Microbiology, 2011: 248418. DOI: https://doi.org/10.1155/2011/248418

Račić I, Spičić S, Galov A, Duvnjak S, Zdelar-Tuk M, Vujnović A, Habrun B, and Cvetnić Z (2014). Identification of Coxiella burnetii genotypes in Croatia using multi-locus VNTR analysis. Veterinary Microbiology, 173:340-347. DOI: https://doi.org/10.1016/j.vetmic.2014.08.016

Raoult D, Bollini G, and Gallais H (1989). Osteoarticular infection due to Coxiella burnetii. Journal of Infectious Disease, 159:1159-1160. DOI: https://doi.org/10.1093/infdis/159.6.1159

Rizzo F, Vitale N, Ballardini M, Borromeo V, Luzzago C, Chiavacci L, and Mandola ML (2016). Q fever seroprevalence and risk factors in sheep and goats in northwest Italy. Preventive Veterinary Medicine, 130: 10-17. DOI: https://doi.org/10.1016/j.prevetmed.2016.05.014

Rodolakis A (2004). Agents abortifs des ruminants et santé publique : Un vaccin en phase I protégerait mieux contre la fièvre Q. Point vétérinaire, pp. 12-13.

Roest HIJ, Solt CB Van, Tilburg JJHC, Klaassen CHW, Hovius EK, Roest FTF, Vellema P, Brom R Van den, and Zijderveld FG Van (2013). Search for possible additional reservoirs for human $Q$ fever, The Netherlands. Emerging Infectious Diseases, 19: 834-835. DOI: https://doi.org/10.3201/eid1905.121489

Runge M, Hilbert A, and Henning K (2012). Contribution to the occurrence of Coxiella burnetii-infection in horses. Praktische Tierarzt, 93: $220-222$. Available at: https://www.cabdirect.org/globalhealth/abstract/20123094548

Selim A, and Ali AF (2020). Seroprevalence and risk factors for C. burentii infection in camels in Egypt. Comparative Immunology, Microbiology and Infectious Diseases, 68:101402. DOI: https://doi.org/10.1016/j.cimid.2019.101402

Seo M-G, Lee S-H, VanBik D, Ouh I-O, Yun S-H, Choi E, Park Y-S, Lee S-E, Kim JW, Cho G-J et al. (2016). Detection and Genotyping of Coxiella burnetii and Coxiella-Like Bacteria in Horses in South Korea. PLoS ONE, 11: e0156710. DOI: https://doi.org/10.1371/journal.pone.0156710

Tissot Dupont H, Raoult D, Brouqui P, Janbon F, Peyramond D, Weiller PJ, Chicheportiche C, Nezri M, and Poirier R (1992). Epidemiologic features and clinical presentation of acute Q fever in hospitalized patients: 323 French cases. The American Journal of Medicine, 93:427-434. DOI: https://doi.org/10.1016/0002-9343(92)90173-9

Tissot Dupont H, Torres S, Nezri M, and Raoult D (1999). Hyperendemic focus of Q fever related to sheep and wind. American Journal of Epidemiology, 150: 67-74. DOI: https://doi.org/10.1093/oxfordjournals.aje.a009920

Toledo A, Jado I, Olmeda AS, Casado-Nistal MA, Gil H, Escudero R, and Anda P (2008). Detection of Coxiella burnetii in ticks collected from central Spain. Vector-Borne and Zoonotic Diseases, 9: 465-468. DOI: https://doi.org/10.1089/vbz.2008.0070

Ullah Q, El-Adawy H, Jamil T, Jamil H, Qureshi ZI, Saqib M, Ullah S, Shah MK, Khan AZ, Zubair M et al. (2019). Serological and molecular investigation of Coxiella burnetii in small ruminants and ticks in Punjab, Pakistan. International Journal of Environmental Research and Public Health, 16: 4271. DOI: https://doi.org/10.3390/ijerph16214271

Yahiaoui WI, Afri-Bouzebda F, Bouzebda Z, and Dahmani A (2013). Sondage sérologique de la fièvre Q chez les ovins par la méthode ELISA et prévalence des avortements dans la région de Ksar El Boukhari (Algérie). Tropicultura, 32: 22-27. Available at: http://www.tropicultura.org/text/v32n1/22.pdf 
Zotov AP, Chumakov MP, Markov AA, Stepanova NI, and Petrov AN (1956). The experimental reproduction of Q-fever and serological studies. Veterinariya, 1956: 44-53. 